\title{
IDENTIFIKASI MISKONSEPSI IPA MENGGUNAKAN SOAL ESAI BAGI SISWA CERDAS ISTIMEWA DI SD MUHAMMADIYAH CONDONGCATUR SLEMAN
}

\author{
Yunita Ariyastuti ${ }^{\mathrm{a}}$ \& Fitri Yuliawati ${ }^{\mathrm{b}, 1}$ \\ a\& b PGMI FITK UIN Sunan Kalijaga Yogyakarta \\ Ifitriyulia50@gmail.com
}

\begin{tabular}{|c|c|}
\hline \multirow{4}{*}{ 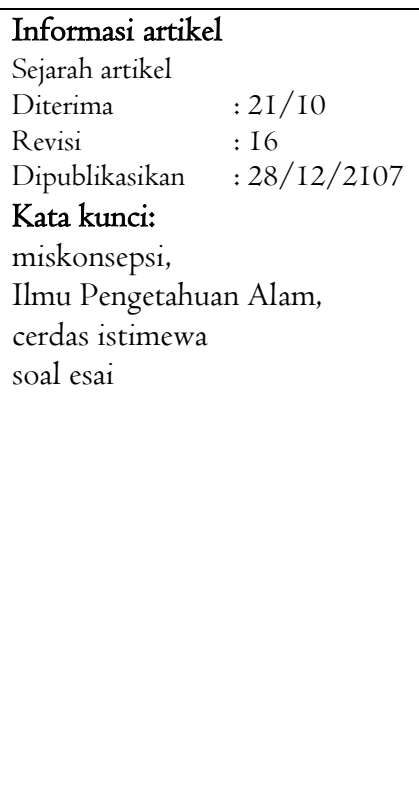 } & ABSTRAK \\
\hline & $\begin{array}{l}\text { Miskonsepsi atau salah konsep mentukan suatu konsep yang tidak sesuai } \\
\text { dengan pengertian ilmiah atau pengertian yang diterima para pakar dalam } \\
\text { bidang itu. Permasalahan yang dikaji dalam penelitian ini adalah miskonsepsi } \\
\text { apa saja yang terjadi pada mata pelajaran Ilmu Pengetahuan Alam siswa } \\
\text { Cerdas Istimewa di SD Muhammadiyah Condongcatur. }\end{array}$ \\
\hline & $\begin{array}{l}\text { Jenis penelitian ini adalah deskriptif dengan pendekatan kuantitatif yang } \\
\text { dilakukan dengan cara mengadakan identifikasi miskonsepsi IPA } \\
\text { menggunakan soal esai terhadap siswa kelas Cerdas Istimewa IPA. Data } \\
\text { yang diperoleh dalam penelitian ini meliputi: partisipasi siswa kelas } \\
\text { Cerdas Istimewa IPA dalam menjawab soal esai, hasil wawancara dengan } \\
\text { guru, dan dokumentasi. Analisis data yang digunakan adalah analisis } \\
\text { deskriptif kuantitatif. }\end{array}$ \\
\hline & $\begin{array}{l}\text { Hasi penelitian menunjukkan miskonsepsi IPA yang terjadi pada siswa } \\
\text { Cerdas Istimewa Di SD Muhammadiyah Condongcatur Sleman pada konsep } \\
\text { bentuk dan fungsi bagian tubuh pada hewan dan tumbuhan dengan } \\
\text { persentase } 62,5 \%, 37,5 \% \text {, dan } 37,5 \% \text {, miskonsepsi pada konsep gaya } \\
\text { sebesar } 25 \% \text { dan } 12,5 \% \text {. }\end{array}$ \\
\hline \multirow{4}{*}{$\begin{array}{l}\text { Key word: } \\
\text { misconception, } \\
\text { natural Sciences, } \\
\text { Intelligence } \\
\text { essay }\end{array}$} & ABSTRACT \\
\hline & $\begin{array}{l}\text { Misconceptions or misconceptions are concepts that are inconsistent with } \\
\text { the scientific understanding or understanding received by the experts in } \\
\text { that field. The problems studied in this research are misconception what } \\
\text { happened to subject of Natural Sciences of Intelligent Student in SD } \\
\text { Muhammadiyah Condongcatur. }\end{array}$ \\
\hline & $\begin{array}{l}\text { The type of this research is descriptive with quantitative approach which is } \\
\text { done by identifying natural Sciences misconception using essay question to } \\
\text { students of Intellectual Intelligent class of natural Sciences. The data } \\
\text { obtained in this study include: the participation of Intellectual natural } \\
\text { Sciences class students in answering essays, interviews with teachers, and } \\
\text { documentation. Data analysis used is quantitative descriptive analysis. }\end{array}$ \\
\hline & $\begin{array}{l}\text { The result of the research shows the misconception of natural Sciences } \\
\text { that happened to the students of Intelligent Special In SD Muhammadiyah } \\
\text { Condongcatur Sleman on the concept of shape and function of body parts } \\
\text { in animals and plants with percentage } 62,5 \%, 37,5 \% \text {, and } 37,5 \% \text {, } \\
\text { misconception on force concept equal to } 25 \% \text { and } 12.5 \% \text {. }\end{array}$ \\
\hline
\end{tabular}

\section{Pendahuluan}

Miskonsepsi atau salah konsep menunjuk pada suatu konsep yang tidak sesuai dengan pengertian ilmiah atau pengertian yang diterima para pakar dalam bidang itu. Bentuknya dapat berupa konsep awal, 
kesalahan, hubungan yang tidak benar antara konsep-konsep, gagasan intuitif atau pandangan yang naif (Sumaji, 1998: 95). Miskonsepsi itu terjadi karena siswa sudah membawa pengetahuan sendiri sebelum ia mendapatkannya di sekolah. Jadi, antara pengetahuan awam dan konsep teori yang siswa terima di sekolah sering kali tidak singkron.

Banyak peneliti menemukan bahwa siswa telah mempunyai miskonsepsi atau konsep alternatif sebelum mereka memperoleh pelajaran formal (Suparno, 2013: 6). Konsep-konsep yang salah tersebut akan terbawa atau mempengaruhi konsep pada tingkat berikutnya, sehingga akan terjadi rantai kesalahan konsep yang tidak terputus karena konsep awal yang telah dimiliki siswa akan menjadi dasar belajar konsep berikutnya. Maka miskonsepsi itu harus diatasi.

Salah pengertian atau konsep alternatif dapat berasal dari siswa sendiri (konsep awal sebelum pelajaran, pengalaman, kemampuan dan minat) dari guru yang juga punya salah pengertian dan salah mengajar, serta dari buku yang digunakan. Secara filosofis adanya konsep alternatif atau salah pengertian pada siswa dapat dijelaskan dengan filsafat konstruktivisme. Filsafat ini menyatakan bahwa pengetahuan dibentuk oleh siswa sendiri dalam kontak dengan lingkungan, tantangan, dan bahan yang dihadapi. Jadi, siswa sudah mengkonstruksi sendiri pengetahuan sesuai pengalaman hidupnya, sebelum mereka mendapatkan pelajaran formal tentang bahan tersebut (Sumaji, I998: I02). Bahkan miskonsepsi itu menghinggapi semua level, dari siswa sekolah dasar sampai mahasiswa. Oleh sebab itu, pembetulan miskonsepsi perlu dilakukan disemua level dan sasaran tersebut.

Konsep adalah suatu gugusan atau sekelompok fakta/keterangan yang memilki makna (Suyono dan Haryanto, 20II: I45). Konsepsi berasal dari kata to conceive yang artinya cara menerima (Samatowa, 20I I: 53). Jadi, konsepsi itu merupakan cara menerima seseorang terhadap suatu hal yang memiliki makna. Miskonsepsi atau salah konsep menunjuk pada sutu konsep yang tidak sesuai dengan pengertian ilmiah para pakar dalam bidang itu. Misalnya, siswa berpendapat bahwa ketika seseorang mendorong mobil dan mobil belum bergerak tidak ada gaya yang bekerja pada mobil. Konsep tersebut salah, meskipun mobil tidak bergerak, telah terjadi gaya pada mobil yang diakibatkan oleh dorongan (Suparno, 2013:4).

Menurut filsafat konstruktivisme pengetahuan itu adalah bentukan (konstruksi) kita sendirinya yang sedang menekuninya. Pengetahuan merupakan akibat dari suatu kostruksi kognitif melahi kegiatan berpikir seseorang (Suparno, 2013: 4). Dalam proses itu siswa menyesuaikan konsep dan ide-ide baru yang mereka pelajari dengan kerangka berpikir yang telah mereka milki. Siswa biasanya sudah membawa konsep-konsep sebelum mereka mengikuti pelajaran formal di sekolah. Kadang konsep-konsep yang mereka bawa itu tidak tepat dan tidak sesuai dengan pengertian para ahli, itulah yang disebut miskonsepsi(Suparno, 2013: 19-20).

Secara garis besar, penyebab miskonsepsi dapat dibagi dalam lima kelompok yaitu:

a. Dari siswa, seperti prakonsepsi awal, kemampuan, tahap perkembangan, minat, cara berpikir, dan teman lain.

b. Dari guru berupa ketidakmampuan guru, kurangnya penguasaan bahan, cara mengajar yang tidak tepat atau sikap guru yang kurang baik dalam berelasi dengan siswa.

c. Dari buku teks, berupa penjelasan atau uraian yang salah dalam buku, tingkat kesulitan penulisan buku terlalu tinggi bagi siswa, buku fiksi sains kadang-kadang konsepnya menyimpang demi menarik pembaca, dan kartun sering membuat miskonsepsi.

d. Dari konteks, seperti budaya, agama, bahasa sehari-hari dan konteks hidup siswa.

e. Metode mengajar yang hanya menekankan kebenaran satu segi, tidak mengungkapkan miskonsepsi siswa, hanya berisi ceramah atau menulis, tidak mengoreksi PR yang salah, model demonstrasi yang sempit dan non-multiple intelligences (Suparno, 2013: 53). 
Untuk mengetahui terjadinya miskonsepsi maka perlu mengetahui derajat pemahaman konsep peserta didik. Abraham tahun 1992 (Das Salirawati dan Antuni Wiyarsi, 20I2: I24) menggolongkan derajat pemahaman peserta didik menjadi enam kategori berdasarkan tes yang diberikan padanya, yaitu:

Tabel I. Derajat Pemahaman Konsep Peserta Didik

\begin{tabular}{|c|c|c|}
\hline No & Tingkat Pemahaman & Kriteria untuk Penilaian \\
\hline $\mathrm{I}$ & Tidak ada respon & Tidak menjawab atau menjawab "saya tidak tahu" \\
\hline 2 & Tidak 1 & $\begin{array}{l}\text { Mengulang pertanyaan, } \\
\text { berhubungan dengan pertanyaan } \\
\text { dan atau jawaban tidak jelas }\end{array}$ \\
\hline 3 & Miskor & Menjawab tetapi penjelas annya tidak benar atau tidak logis \\
\hline 4 & $\begin{array}{l}\text { Memahami sebagian dan } \\
\text { terjadi miskonsepsi }\end{array}$ & $\begin{array}{l}\text { Jawaban menunjukkan ada konsep yang dikuasai, namu } \\
\text { ada pernyataan yang menunjukkan miskonsepsi }\end{array}$ \\
\hline 5 & Memahami sebagian & $\begin{array}{l}\text { Jawaban menunjukkan hanya } \\
\text { dipahami tanpa miskons epsi }\end{array}$ \\
\hline 6 & Memahami konsep & Menunjukkan kons ep dikuasai dengan benar \\
\hline
\end{tabular}

Lebih lanjut Abraham mengkategorikan derajat pemahaman I dan 2 termasuk tidak memahami, 3 dan 4 termasuk miskonsepsi, 5 dan 6 termasuk memahami. Hal ini sesuai yang dikemukakan Feldsine (Das Salirawati dan Antuni Wiyarsi, 20I2: I25) bahwa miskonsepsi sebagai suatu kesalahan akibat hubungan tidak benar antar konsep dan pendapat Fowler \& Jaoude yang menyatakan salah satu bentuk miskonsepsi adalah adanya hubungan hirarkhis konsep-konsep yang tidak benar. Ketidakjelasan dan ketidaklogisan jawaban peserta didik disebabkan penguasaan suatu konsep yang salah yang berakibat pada kesalahan keseluruhan konsep yang ada, padahal ada keterkaitan yang erat antar konsep dalam suatu materi ajar.

Setelah mengetahui derajat pemahaman konsep peserta didik maka perlu mengetahui alat yang digunakan untuk mendeteksi miskonsepsi. Alat yang dapat digunakan peneliti dan guru untuk mendeteksi miskonsepsi yaitu(Suparno, 2013: I2I-I28):

a. Peta konsep, sebagaimana diungkapkan Novak dkk., dalam buku yang berjudul Miskonsepsi \& Perubahan Konsep Dalam Pendidikan Fiska karya Paul Suparno menjelaskan bahwa peta konsep menekankan hubungan antara konsep-konsep dan menekankan gagasangagasan pokok, yang disusun hirarkis, dengan jelas dan dapat mengungkap miskonsepsi siswa yang digambarkan dalam peta konsep. Untuk mendapatkan alasan yang lebih baik lagi, peta konsep digabungkan dengan wawancara klinis.

b. Tes multiple choice dengan reasoning terbuka, sebagaimana diungkapkan Amir dkk dalam buku yang berjudul Miskonsepsi \& Perubahan Konsep Dalam Pendidikan Fiska karya Paul Suparno, bahwa mereka menggunakan tes pilihan ganda dengan pertanyaan terbuka dimana siswa harus menjawab dan menulis mengapa siswa mempunyai jawaban seperti itu.

c. Tes esai tertulis, peneliti atau guru mempersiapkan suatu tes esai yang memuat beberapa konsep yang hendak diajarkan atau sudah diajarkan. Dari tes tersebut dapat diketahui miskonsepsi yang dibawa siswa dan dalam bidang apa.

d. Wawancara diagnosis, yaitu dilakukan dengan cara guru atau peneliti memilih beberapa konsep yang diperkirakan sulit dimengerti siswa, atau beberapa konsep pokok dari bahan yang 
hendak diajarkan. Dari konsep- konsep tersebut disusun pertanyaan, lalu ditanyakan langsung kepada siswa

e. Diskusi dalam kelas, yaitu dilakukan dengan cara siswa diminta mengungkapkan gagasan mereka tentang konsep yang sudah diajarkan atau hendak diajarkan, dan setiap siswa dibantu agar berani berbicara untuk mengungkapkan pikiran mereka tentang persoalan yang dibahas.

f. Praktikum dengan tanya jawab, yaitu ketika praktikum berlangsung guru atau peneliti selahu bertanya bagaimana konsep siswa dan bagaimana siswa menjelaskan persoalan dalam praktikum tersebut.

Peneliti membatasi fokus penelitian yaitu pada kompetensi inti dan kompetensi dasar Ilmu Pengetahuan Alam SD/MI kelas IV.

Kompetensi Inti:

3. Memahami pengetahuan faktual dengan cara mengamati dan menanya berdasarkan rasa ingin tahu tentang dirinya, makhluk ciptaan Tuhan dan kegiatannya, dan benda-benda yang dijumpainya di rumah, di sekolah dan tempat bermain.

Kompetensi Dasar:

3.I Menganalisi hubungan antara bentuk dan fungsi bagian tubuh pada hewan dan tumbuhan. 3.2 Membandingkan siklus hidup beberapa jenis makhluk hidup serta mengaitkan dengan upaya pelestariannya. 3.3 Mengidentifikasi macam- macam gaya, antara lain: gaya otot, gaya listrik, gaya magnet, gaya gravitasi, dan gaya gesekan. 3.4 Menghubungkan gaya dengan gerak pada peristiwa di lingkungan sekitar.

\section{Metode Penelitian}

Jenis penelitian yang digunakan adalah penelitian deskriptif dengan pendekatan kuantitatif.. Adapun teknik pengumpulan data yang digunakan dalam penelitian ini yaitu tes dan wawancara:

\section{Tes}

Tes adalah instrumen atau alat untuk mengumpulkan data tentang kemampuan subjek penelitian dengan cara pengukuran, misalnya untuk mengukur kemampuan subjek penelitian dalam menguasai materi pelajaran. Tes yang digunakan dalam penelitian ini adalah tes subyektif berbentuk esai atau uraian yang dilengkapi dengan skala pengukuran. Skala pengukuran yang digunakan dalam penelitian ini yaitu skala Guttman. Skala Guttman adalah skala yang digunakan untuk jawaaban yang bersifat tegas (jelas) dan konsisten. Alternatif jawaban pada jenis skala ini hanya terdiri dari dua alternatif. Contoh: Benar-salah, ya-tidak, yakin-tidak yakin, positif- negatif, sedangkan untuk jawaban responden angka tertinggi I dan angka terendah 0 . Pada penelitian ini terdapat tiga skala Guttman yang digunakan yaitu untuk jawaban ya/tidak, menjawab benar I menjawab salah 0 . Untuk jawaban alasan menjawab benar nilai I menjawab salah nilai 0 . Untuk perpaduan jawaban antara jawaban ya/tidak dan jawaban alasan yaitu jika jawaban dan alasan sama nilainya diberi nilai 0 dan untuk jawaban ya/tidak dan alasan jawaban terdapat perbedaan nilainya diberi nilai I. Pada skala Guttman yang ketiga jika nilainya I berarti terjadi miskonsepsi dan jika nilainya 0 berarti tidak terjadi miskonsepsi.

\section{Wawancara}

Pada penelitian ini menggunakan jenis wawancara formal, karena peneliti menyusun terlebih dahulu daftar pertanyaan, dan juga mengadakan perjanjian dengan guru yang akan menjadi sumber yang akan diwawancaraiuntuk mendapatkan data tentang penyebab terjadinya miskonsepsi pada siswa. 
Analisis yang digunakan dalam penelitian ini adalah analisis statistik deskriptif. Teknik analisis statistik deskriptif yang dapat digunakan antara lain:

I. Penyajian data dalam bentuk tabel atau distribusi frekuensi dan tabulasi silang (crosstab). Peneliti melakukan penyajian data dalam bentuk tabel. Penyajian data dalam bentuk tabel menggunakan alat bantu yaitu Microsoft Excel 2013 serta tabel distribusi frekuensi menggunakan alat bantu IBM SPSS Statistics 22.

2. Penyajian data dalam bentuk visual seperti histogram, grafik, diagram batang, diagram lingkaran, diagram pastel (pie chart), line chart dan diagram lambang. Peneliti melakukan penyajian data dalam bentuk visual yaitu line chart dengan bantuan Microsoft Excel2013.

3. Penghitungan ukuran tendensi sentral (mean, median, dan modus). Peneliti melakukan penghitungan tendensi sentral yaitu menghitung mean, median, dan modus pada data yang ditemukan adanya miskonsepsi siswa dengan alat bantu IBM SPSS Statistics 22.

4. Penghitungan ukuran letak (kuartil, desil, persen dan persentil). Pada penelitian ini peneliti melakukan perhitungan ukuran letak yaitu persen pada data yang ditemukan adanya miskonsepsi siswa dengan alat bantu Microsoft Excel20I3.

5. Penghitungan ukuran penyebaran data (deviasi standar, varian, range, deviasi kuartil, dan sebagainya). Peneliti melakukan penghitungan ukuran penyebaran data yaitu deviasi standar, varian, range, dan sum pada data yang ditemukan adanya miskonsepsi siswa dengan alat bantu IBM SPSS Statistics 22.

\section{Hasil dan Pembahasan}

Data yang diperoleh dari hasil tes cek pemahaman bentuk esai peserta didik dianalisis dengan mengadopsi kategori miskonsepsi Abraham sebagaimana dalam Das Salirawati dan Antuni Wiyarsi. Data pola jawaban peserta didik selanjutnya dimasukkan ke dalam kategori derajat pemahaman konsep sebagai berikut:

Tabel 3 Derajat Pemahaman Konsep

\begin{tabular}{|c|c|c|c|}
\hline No & $\begin{array}{c}\text { Tingkat } \\
\text { Pemahaman }\end{array}$ & Kriteria untuk Penilaian & Pola Jawaban \\
\hline $\mathrm{I}$ & Miskons epsi & $\begin{array}{l}\text { Jawaban menunjukkan ada konsep } \\
\text { yang dikuasai, namun ada } \\
\text { pernyataan yang menunjukkan } \\
\text { miskonsepsi }\end{array}$ & $\begin{array}{l}\text { Jawaban salah alas an benar dan } \\
\text { jawaban benar alas an salah }\end{array}$ \\
\hline 2 & Memahami & $\begin{array}{l}\text { Menunjukkan kons ep dikuas ai } \\
\text { dengan benar }\end{array}$ & Jawaban benar alas an benar \\
\hline 3 & Tidak memahami & $\begin{array}{l}\text { Tidak menjawab, menjawab tidak } \\
\text { berhubungan dengan pertanyaan }\end{array}$ & $\begin{array}{l}\text { Jawaban salah, alasan salah } \\
\text { Jawaban benar tidak ada alasan } \\
\text { Jawaban salah tidak ada alasan }\end{array}$ \\
\hline
\end{tabular}


Kisi-kisi soal yang digunakan untuk melakukan tes pemahaman konsep adalah sebagai berikut:

Tabel 2 Kisi-Kisi Soal Tes Pemahaman Konsep

\begin{tabular}{|c|c|c|c|c|}
\hline Kompetensi Dasar & Indikator & $\begin{array}{l}\text { Nomor } \\
\text { Soal }\end{array}$ & $\begin{array}{c}\text { Klasifikasi } \\
\text { Soal }\end{array}$ & Soal \\
\hline \multirow{3}{*}{$\begin{array}{l}\text { 3.I } \\
\text { Menganalisis } \\
\text { hubungan antara } \\
\text { bentuk dan } \\
\text { fungsi bagian } \\
\text { tubuh pada } \\
\text { hewan dan } \\
\text { tumbuhan }\end{array}$} & $\begin{array}{l}\text { 3.I.I Peserta } \\
\text { didik mampu } \\
\text { menentukan bentuk } \\
\text { tubuh hewan } \\
\text { berdasarkan fungsinya } \\
\text { dengan benar }\end{array}$ & I & C3 & $\begin{array}{l}\text { Paruh burung pipit tajam } \\
\text { dan kuat berfungsi untuk } \\
\text { memecah biji-bijian. }\end{array}$ \\
\hline & $\begin{array}{l}\text { 3.I.2 Peserta } \\
\text { didik mampu } \\
\text { menentukan bentuk } \\
\text { tubuh tumbuhan } \\
\text { berdasarkan fungsinya } \\
\text { dengan benar }\end{array}$ & 2 & C3 & $\begin{array}{l}\text { Tumbuhan enceng } \\
\text { gondong dan teratai } \\
\text { memiliki bentuk daun yang } \\
\text { sama untuk memperbesar } \\
\text { proses penguapan air dari } \\
\text { dalam tubuhnya. }\end{array}$ \\
\hline & $\begin{array}{l}\text { 3.I.3 Peserta } \\
\text { didik mampu } \\
\text { menganalisis bentuk } \\
\text { bagian tubuh beberapa } \\
\text { hewan berdasarkan } \\
\text { fungsinya dengan } \\
\text { benar } \\
\text { 3.I.4 Peserta } \\
\text { didik mampu } \\
\text { menjelaskan hubungan } \\
\text { antara bentuk dan } \\
\text { fungsi bagian tubuh } \\
\text { pada tumbuhan } \\
\text { dengan tepat }\end{array}$ & 3,4 & $\mathrm{C} 2$ & $\begin{array}{l}\text { Kupu-kupu dan nyamuk } \\
\text { memiliki bentuk mulut } \\
\text { sama yaitu panjang dan } \\
\text { runcing, berfungsi untuk } \\
\text { menghisap makanan. }\end{array}$ \\
\hline \multirow{3}{*}{$\begin{array}{l}3.2 \\
\text { Membandingkan } \\
\text { siklus hidup } \\
\text { beberapa } \\
\text { jenis makhluk } \\
\text { hidup } \\
\text { serta } \\
\text { mengaitkan dengan } \\
\text { upaya } \\
\text { pelestariannya }\end{array}$} & $\begin{array}{l}\text { 3.2.I Peserta } \\
\text { didik mampu } \\
\text { mengemukakan } \\
\text { perbedaan } \\
\text { siklus tumbuhan } \\
\text { paku dan lumut } \\
\text { dengan benar }\end{array}$ & 6 & $\mathrm{C} 2$ & $\begin{array}{l}\text { Batang kaktus tebal dan } \\
\text { tersusun oleh jaringan } \\
\text { spon berfungsi untuk } \\
\text { menyimpan cadangan air. }\end{array}$ \\
\hline & $\begin{array}{l}\text { 3.2.2 Peserta } \\
\text { didik mampu } \\
\text { menganalisis siklus } \\
\text { hidup suatu makhluk } \\
\text { hidup dengan benar }\end{array}$ & 7,8 & $\mathrm{C} 4$ & $\begin{array}{l}\text { Siklus hidup pohon } \\
\text { mangga yaitu pohon } \\
\text { mangga berbunga - } \\
\text { berbuah-biji ditanam- } \\
\text { tumbuh akar dan tunas- } \\
\text { pohon kecil. } \\
\text { Siklus hidup capung } \\
\text { berawal dari telur. }\end{array}$ \\
\hline & $\begin{array}{l}3.2 .3 \text { Peserta } \\
\text { didik mampu } \\
\text { mengaitkan siklus } \\
\text { hidup dengan upaya } \\
\text { pelestariannya }\end{array}$ & 9 & $\mathrm{C} 4$ & $\begin{array}{l}\text { Tidak berburu ketika } \\
\text { musim berkembang biak } \\
\text { merupakan salah satu upaya } \\
\text { pelestarian hewan. }\end{array}$ \\
\hline
\end{tabular}




\begin{tabular}{|c|c|c|c|c|}
\hline Kompetensi Dasar & Indikator & $\begin{array}{c}\text { Nomor } \\
\text { Soal }\end{array}$ & $\begin{array}{c}\text { Klasifikasi } \\
\text { Soal }\end{array}$ & Soal \\
\hline \multirow{7}{*}{$\begin{array}{l}3.3 \\
\text { Mengidentifikasi } \\
\text { macam-macam } \\
\text { gaya, antara } \\
\text { lain: gaya otot, } \\
\text { gaya listrik, gaya } \\
\text { magnet, gaya } \\
\text { gravitasi, } \\
\text { dan gaya gesekan }\end{array}$} & $\begin{array}{l}\text { 3.2.4 Peserta } \\
\text { didik } \\
\text { mampu } \\
\text { mengemukakan } \\
\text { persamaan siklus } \\
\text { hidup hewan dengan } \\
\text { benar }\end{array}$ & I0 & C2 & $\begin{array}{l}\text { Kecoa dan jangkrik } \\
\text { memiliki siklus hidup yang } \\
\text { sama pada fase nimfa yaitu } \\
\text { metamorfosis tidak } \\
\text { sempurna. }\end{array}$ \\
\hline & \multirow{4}{*}{$\begin{array}{l}\text { 3.3.I Peserta } \\
\text { didik } \\
\text { mampu menguraikan } \\
\text { suatu gaya } \\
\text { berdasarkan aktivitas } \\
\text { yang terjadi dengan } \\
\text { benar }\end{array}$} & \multirow{4}{*}{$\begin{array}{l}\text { II, I2, } \\
\text { I3,I7 }\end{array}$} & \multirow{4}{*}{$\mathrm{C} 2$} & $\begin{array}{l}\text { Terjadi gaya gesek ketika } \\
\text { mengerem sepeda. }\end{array}$ \\
\hline & & & & $\begin{array}{l}\text { Pemain selancar dapat } \\
\text { meluncur di atas } \\
\text { permukaan es karena } \\
\text { adanya satu gaya yaitu } \\
\text { gaya gesekan }\end{array}$ \\
\hline & & & & $\begin{array}{l}\text { Bola dapat melambung ke } \\
\text { atas ketika ditendang } \\
\text { karena pengaruh satu gaya } \\
\text { yaitu gaya otot. }\end{array}$ \\
\hline & & & & $\begin{array}{l}\text { Penggaris mika yang } \\
\text { digosokkan pada rambut } \\
\text { yang kering sehingga } \\
\text { dapat menarik potongan } \\
\text { kertas yang kecil-kecil } \\
\text { karena adanya gaya listik. }\end{array}$ \\
\hline & $\begin{array}{l}\text { 3.3.2 Peserta } \\
\text { didik } \\
\text { mampu membedakan } \\
\text { macam gaya } \\
\text { berdasarkan kegiatan } \\
\text { yang tejadi dengan } \\
\text { benar }\end{array}$ & $\mathrm{I} 4$ & $\mathrm{C} 2$ & $\begin{array}{l}\text { Orang memanjat pohon } \\
\text { gaya yang timbul yaitu } \\
\text { gaya otot dan saat } \\
\text { melompat karena adanya } \\
\text { gaya gravitasi. }\end{array}$ \\
\hline & $\begin{array}{l}\text { 3.3.3 Peserta } \\
\text { didik } \\
\text { dapat menentukan } \\
\text { gaya yang terjadi pada } \\
\text { jarum yang menempel } \\
\text { pada ujung gunting } \\
\text { dengan benar }\end{array}$ & I5 & C3 & $\begin{array}{l}\text { Jarum akan menempel } \\
\text { pada ujung gunting yang } \\
\text { mengandung magnet }\end{array}$ \\
\hline $\begin{array}{l}3.4 \\
\text { Menghubungkan } \\
\text { gaya dengan gerak } \\
\text { pada peristiwa } \\
\text { di lingkungan } \\
\text { sekitar }\end{array}$ & $\begin{array}{l}\text { 3.4.I Peserta } \\
\text { didik } \\
\text { mampu } \\
\text { menyimpulkan } \\
\text { hubungan gaya dan } \\
\text { gerak dalam suatu } \\
\text { peristiwa dengan } \\
\text { benar }\end{array}$ & 16 & $\mathrm{C} 5$ & $\begin{array}{l}\text { Mendorong mobil mogok } \\
\text { mengakibatkan mobil } \\
\text { dapat bergerak. }\end{array}$ \\
\hline
\end{tabular}




\begin{tabular}{|c|c|c|c|c|}
\hline Kompetensi Dasar & Indikator & $\begin{array}{c}\text { Nomor } \\
\text { Soal }\end{array}$ & $\begin{array}{l}\text { Klasifikasi } \\
\text { Soal }\end{array}$ & Soal \\
\hline & $\begin{array}{l}\text { 3.4.2 Peserta } \\
\text { didik } \\
\text { mampu mengaitkan } \\
\text { hubungan gaya dan } \\
\text { gerak pada suatu } \\
\text { peristiwa dengan } \\
\text { benar }\end{array}$ & $\begin{array}{c}\text { I8, I9, } \\
20\end{array}$ & C3 & $\begin{array}{l}\text { Meja didorong dapat } \\
\text { bergerak } \\
\text { Saat pemain bola } \\
\text { menyundul bola, bola } \\
\text { berubah arah }\end{array}$ \\
\hline & & & & $\begin{array}{l}\text { Permainan jungkat-jungkit } \\
\text { dapat digunakan karena } \\
\text { adanya gaya dan gerak }\end{array}$ \\
\hline
\end{tabular}

Data hasil uji coba soal tes cek pemahaman berbentuk esai sebagai berikut:

Tabel 4. Rincian Jawaban Butir Soal Nomor 3

\begin{tabular}{|c|c|c|c|}
\hline No & Siswa & $\begin{array}{l}\text { Jawaban } \\
\text { Ya/tidak }\end{array}$ & Alas an \\
\hline I & A & Tidak & $\begin{array}{l}\text { Karena kura-kura juga tinggal di daratan dan bentuk kaki } \\
\text { penyu lebih panjang }\end{array}$ \\
\hline 2 & B & Tidak & Karena kura-kura di darat dan air \\
\hline 3 & $\mathrm{C}$ & Tidak & Kaki kura-kura seperti kaki dan kura-kura bis a hidup di darat \\
\hline 4 & $\mathrm{D}$ & Ya & $\begin{array}{l}\text { Karena kaki berselaput kura-kura dan penyu dapat } \\
\text { membantu mereka berenang }\end{array}$ \\
\hline 5 & $\mathrm{E}$ & Ya & $\begin{array}{l}\text { Karena bila kaki mereka tidak berbentuk lebar mereka } \\
\text { akan kesulitan berenang }\end{array}$ \\
\hline 6 & $\mathrm{~F}$ & Ya & Karena kura-kura dan penyu sering menghabis kan waktu di air \\
\hline 7 & G & Ya & $\begin{array}{l}\text { Karena kaki ters ebut telah dis esuaiakan dengan fungsinya } \\
\text { yaitu berenang dan berjalan ( menopang cangkang yang } \\
\text { berat) }\end{array}$ \\
\hline 8 & $\mathrm{H}$ & Tidak & $\begin{array}{l}\text { Penyu lebih seperti sirip karena tinggalnya di lautan dan } \\
\text { suka menjelajahi }\end{array}$ \\
\hline
\end{tabular}

Berdasarkan jawaban subjek uji coba dalam Tabel 4, terdapat jawaban yang termasuk dalam kategori tingkat miskonsepsi. Jadi, peserta didik masih mengalami miskonsepsi pada butir soal nomor 3 . Terdapat 5 peserta didik yang mengalami miskonsepsi.

Tabel 5. Rincian Jawaban Butir Soal Nomor 4

\begin{tabular}{cccc}
\hline No & Sis wa & $\begin{array}{c}\text { Jawaban } \\
\text { Ya/tidak }\end{array}$ & Alasan \\
\hline I & A & Ya & Karena untuk mengurangi penguapan dan menyimpan air \\
2 & B & Ya & $\begin{array}{l}\text { Karena kaktus hidup di tempat yang kurang air dan } \\
\text { makanan jadi harus menyimpan di batangnya }\end{array}$ \\
\hline
\end{tabular}




\begin{tabular}{|c|c|c|c|}
\hline 3 & $\mathrm{C}$ & $\mathrm{Ya}$ & $\begin{array}{l}\text { Karena kaktus tinggal di gurun sehingga perlu jaringan } \\
\text { pon agar memiliki cadangan air }\end{array}$ \\
\hline 4 & $\mathrm{D}$ & $\mathrm{Ya}$ & $\begin{array}{l}\text { Karena kaktus hidup di daerah kering yang jarang ada } \\
\text { air, jadi mereka harus mengurangi penguapan }\end{array}$ \\
\hline 5 & $\mathrm{E}$ & Ya & $\begin{array}{l}\text { Cadangan jair ters ebut harus banyak tersimpan pada batang } \\
\text { kaktus, karena kaktus merupakan tumbuhan xerofit atau } \\
\text { hidup di gurun }\end{array}$ \\
\hline 6 & $\mathrm{~F}$ & $\mathrm{Ya}$ & Karena kaktus hidup di daerah kering \\
\hline 7 & G & $\mathrm{Ya}$ & $\begin{array}{l}\text { Karena kaktus hidup di gurun jadi jaringan spon ini sangat } \\
\text { berfungsi, untuk mencegah kaktus kekurangan air }\end{array}$ \\
\hline 8 & $\mathrm{H}$ & $\mathrm{Ya}$ & Hidup di gurun yang sangat kering dan jarang hujan \\
\hline
\end{tabular}

Berdasarkan jawaban subjek uji coba dalam Tabel 5, terdapat jawaban yang termasuk dalam kategori tingkat miskonsepsi. Jadi, peserta didik masih mengalami miskonsepsi pada butir soal nomor 4. Terdapat 3 peserta didik yang mengalami miskonsepsi.

Tabel 6. Rincian Jawaban Butir Soal Nomor 5

\begin{tabular}{cccl}
\hline No & Siswa & $\begin{array}{c}\text { Jawaban } \\
\text { Ya/tidak }\end{array}$ & \multicolumn{1}{c}{ Alasan } \\
\hline I & A & Ya & Karena mereka tidak punya nectar \\
2 & B & Ya & Karena melalui perkawinan \\
3 & C & Ya & Karena fase sporofit untuk menghas ilkan spora \\
4 & D & Ya & Karena paku dan lumut berkembangbiak dengan spora \\
5 & E & - & Tidak ada jawaban \\
6 & F & Ya & Karena paku dan lumut termas uk tumbuhan sporofit \\
7 & G & Ya & $\begin{array}{l}\text { Karena merupakan fase hidup yang perlu dilakukan agar } \\
\text { tetap seimbang }\end{array}$ \\
8 & H & Tidak & Karena masih belum bisa berkembang biak \\
\hline
\end{tabular}

Berdasarkan jawaban subjek uji coba dalam Tabel 6, terdapat jawaban yang termasuk dalam kategori tingkat miskonsepsi. Jadi, peserta didik masih mengalami miskonsepsi pada butir soal nomor 5 . Terdapat 3 peserta didik yang mengalami miskonsepsi.

Tabel 7. Rincian Jawaban Butir Soal Nomor II

\begin{tabular}{|c|c|c|c|}
\hline No & Sis wa & $\begin{array}{l}\text { Jawaban } \\
\text { Ya/tidak }\end{array}$ & Alasan \\
\hline $\mathrm{I}$ & A & $\mathrm{Ya}$ & $\begin{array}{l}\text { Karena rem itu menghasilkan gesekan pada roda karena } \\
\text { itu sepeda berhenti }\end{array}$ \\
\hline 2 & B & Ya & Karena kita mengerem roda bergesekan dengan jalan \\
\hline 3 & $\mathrm{C}$ & Ya & Karena ada karet yang mengempit ban sepeda \\
\hline 4 & $\mathrm{D}$ & Ya & $\begin{array}{l}\text { Karena saat direm, roda dan jalan berges ekan yang } \\
\text { menimbulkan gaya gesek }\end{array}$ \\
\hline
\end{tabular}




\begin{tabular}{cccl}
5 & E & Ya & $\begin{array}{l}\text { Karena mengerem sepeda berarti memberhentikan, dan } \\
\text { salah satu } \\
\text { fungsi gaya gesek memberhentikan benda }\end{array}$ \\
6 & F & Ya & $\begin{array}{l}\text { Karena yang membuat sepeda benhenti adalah ges ekan } \\
\text { antara roda dengan rem sepeda }\end{array}$ \\
7 & G & Ya & $\begin{array}{l}\text { Karena rem ters ebut berusaha menahan roda sepeda } \\
\text { untuk tidak bisa bergerak dan terjadilah gaya gesek }\end{array}$ \\
8 & H & Ya & Karena gesekan rem yang mengempit sepeda \\
\hline
\end{tabular}

Berdasarkan jawaban subjek uji coba dalam Tabel 7, terdapat jawaban yang termasuk dalam kategori tingkat miskonsepsi. Jadi, peserta didik masih mengalami miskonsepsi pada butir soal nomor II. Terdapat 2 peserta didik yang mengalami miskonsepsi.

Tabel 8. Rincian Jawaban Butir Soal Nomor 12

\begin{tabular}{|c|c|c|c|}
\hline No & Sis wa & $\begin{array}{l}\text { Jawaban } \\
\text { Ya/tidak }\end{array}$ & Alasan \\
\hline $\mathrm{I}$ & A & Ya & Karena agar dapat meluncur \\
\hline 2 & B & Ya & Bila tidak ada gaya gesek pasti tidak bisa meluncur \\
\hline 3 & $\mathrm{C}$ & Tidak & Karena memanfaatkan kelicinan es \\
\hline 4 & $\mathrm{D}$ & Tidak & Karena papannya bergesekan dengan es \\
\hline 5 & $\mathrm{E}$ & Ya & $\begin{array}{l}\text { Karena gayanya tidak hanya gaya gesek namun } \\
\text { dibantu gaya }\end{array}$ \\
\hline 6 & $\mathrm{~F}$ & Tidak & Karena para selancar juga ditarik gaya gravitasi \\
\hline 7 & G & Ya & Karena gaya gesek terjadi oleh tarikan gravitasi \\
\hline 8 & $\mathrm{H}$ & Tidak & $\begin{array}{l}\text { Karena pemain selancar es butuh gaya gravitasi karena } \\
\text { kalau tidak ada gravitasi maka akan melayang }\end{array}$ \\
\hline
\end{tabular}

Berdasarkan jawaban subjek uji coba dalam Tabel 8, terdapat jawaban yang termasuk dalam kategori tingkat miskonsepsi. Jadi, peserta didik masih mengalami miskonsepsi pada butir soal nomor II. Terdapat I peserta didik yang mengalami miskonsepsi.

\section{Kesimpulan}

Berdasarkan hasil penelitian dan pembahasan, dapat diambil kesimpulan sebagai berikut, Miskonsepsi yang terjadi pada siswa Cerdas Istimewa antara lain pada bentuk dan fungsi bagian tubuh pada hewan, persentase sebesar 37,5 yaitu miskonsepsi pada bentuk dan fungsi bagian tubuh pada tumbuhan, serta persentase $25 \%$ dan $12,5 \%$ yaitu miskonsepsi pada identifikasi macam-macam gaya.

\section{Referensi}

Arikunto, Suharsimi 2012. Dasar-Dasar Evaluasi Pendidikan. Jakarta: Bumi Aksara.

Salirawati, Das, dan Wiyarsi, Antuni, "Pengembangan Instrumen Pendeteksi Miskonsepsi Materi Ikatan Kimia Untuk Peserta Didik", Jurnal Kependidikan, Vol 42, No. 2, November 2012, hlm. I20 di http://journaluny.ac.id/index.php/jk/article/viewFile/I946/I597 diakses pada tanggal 4 Juni 2017 pukul I0.I7 WIB. 
Samatowa, Usman. 20I I. Pembelajaran IPA di Sekolah Dasar. Jakarta: Indeks.

Sumaji dkk. 1998. Pendidikan Sains Yang Humanistis. Yogyakarta: Kanisius.

Suparno, Paul. 1997. Filsafat Konstruktivisme Dalam Pendidikan. Yogyakarta: Kanisius.

Suparno, Paul. 2013. Metodologi Pembelajaran Fisika Konstruktivistik \& Menyenangkan. Yogyakarta: Universitas Sanata Darma.

Suparno, Paul. 2013. Miskonsepsi \& Perubahan Konsep Dalam Pendidikan Fisika, Jakarta: Grasindo.

Suyono dan Hariyanto.20I I. Belajar dan Pembelajaran: Teori dan Konsep Dasar. Bandung: Remaja Rosdakarya. 